\title{
Anterior capsule cover and axial movement of intraocular lens
}

MA Nanavaty, SM Raj, VA Vasavada, VA Vasavada and AR Vasavada

\begin{abstract}
Purpose To measure optic shift (OS) of a single piece monofocal intraocular lens (IOL) with varying relationships between anterior capsule cover and IOL optic.

Methods This is a prospective randomized masked study of 150 eyes undergoing phacoemulsification. Eyes received either option: $360^{\circ}$ total capsule cover (group I); partial cover (group II); or no cover (group III). OS was calculated as difference in anterior chamber depth after administration of cyclopentolate $1 \%$ and pilocarpine $2 \%$ on IOLMaster $^{\mathbb{R}}$ at separate visits at 6 months follow-up. Subsequently, using retro-illumination photographs, percentage area of capsule cover was calculated. OS within and between groups I and II was analyzed. The impact of one quartile change in area of capsule cover on percentage change in OS was measured for both groups. Unpaired $t$-test, correlation, and regression were applied. Results In groups I, II, and III, mean age of patients was $56.68 \pm 6.38,57.09 \pm 7.34$,
\end{abstract}

$59.15 \pm 6.35$ years, respectively; mean OS $(\mathrm{mm})$ was $1.25 \pm 0.28,1.20 \pm 0.24 ; 0.95 \pm 0.26$ $(P=0.013)$, respectively; and percentage area of capsule cover $(\%)$ was $47.35 \pm 10.48$, $33.83 \pm 10.11,0.16 \pm 0.13(P=0.001)$, respectively. Mean percentage area of capsule cover in group I vs group II was significant $(P=0.001)$. OS was $1.22 \pm 0.26 \mathrm{~mm}$ in groups I and II (combined) vs $0.95 \pm 0.26 \mathrm{~mm}$ in group III $(P=0.004,(0.06,0.33))$. OS in group I vs group II was not significant $(P=0.46)$. Correlation coefficient was $r=0.38(P<0.001)$. With every increment on quartile (a quartile is any of the three values which divide the sorted data set into four equal parts, so that each part represents one-fourth of the sample or population) class of area of capsule cover the OS increased by $0.12 \mathrm{~mm}$.
Conclusion The OS differed significantly between total and partial cover groups combined $v$ s no cover group.

Eye (2008) 22, 1015-1023; doi:10.1038/sj.eye.6702817; published online 4 May 2007

Keywords: IOL optic; anterior capsule cover; total cover; partial cover; no cover; optic shift

\section{Introduction}

The axial position of an intraocular lens (IOL) of a given power determines its refractive effect. It has been established that a dynamic change in the refractive state of the eye caused by interactions between the contracting ciliary muscles and the zonules-capsular bag-IOL complex, leads to axial shift of the optic (movement of the IOL) and results in improved near vision. This is defined as pseudophakic accommodation. ${ }^{1,2}$ To achieve pseudophakic accommodation, the integrity of the lens capsule, zonule, and ciliary muscles must be preserved. While analyzing this shift in the IOL, some studies have mentioned the anterior capsule cover of the IOL optic edge, ${ }^{3,4}$ whereas others have not made any mention of it. ${ }^{5-9}$ With the increasing use of multifocal IOLs, in which postoperative emmetropia is the main goal, the size of the capsulorhexis (CCC) would be of immense importance as it could influence its refractive power.

The relationship between the sizes of the CCC and the optic shift (OS) is unclear. A study on accommodating IOLs has shown that a larger CCC with a smaller CCC-optic overlap improved visual performance. ${ }^{10}$ There are no reports in peer-reviewed literature of the relationship between the anterior capsule cover on the monofocal IOL optic and the optic shift. lladevi Cataract \& IOL Research Centre, Raghudeep Eye Clinic, Memnagar, Ahmedabad, India

Correspondence:

AR Vasavada,

Iladevi Cataract \& IOL Research Centre,

Gurukul Road, Memnagar, Ahmedabad - 380 052, India

Tel: + 9179 27492303/ +9179 27490909. Fax: +917927411200

E-mail: icirc@

abhayvasavada.com

Received: 18 October 2006 Accepted in revised form: 7 March 2007 Published online: 4 May 2007

This paper was presented in part as a poster at European Society of Cataract and Refractive Surgery 2005, Lisbon. The authors do not have any commercial connection and/or interest in marketing any product, instrument, or piece of equipment discussed in this paper 
Hence, we designed a prospective randomized clinical study to measure the OS of a single piece monofocal IOL (model SA60AT: $6.0 \mathrm{~mm}$ optic diameter and $13.0 \mathrm{~mm}$ overall diameter) with varying relationships between the anterior capsule cover and the IOL optic.

\section{Materials and methods}

\section{Study design}

A prospective, randomized, masked study was performed at Iladevi Cataract and IOL Research Centre. Patients operated from March 2004 to November 2004, were recruited in the study after obtaining approval from the ethics committee and informed consent from the patients.

\section{Sample size}

The sample size was estimated from a past study, ${ }^{11}$ which aimed to assess the influence of the anterior CCC size on the postoperative anterior chamber depth (ACD). At 3 months, postoperatively, they found a significant difference of $0.2 \mathrm{~mm}$ in the ACD between the small and larger anterior CCC. Hence, we decided to consider a difference of $0.2 \mathrm{~mm}$ and above in the optic shift, to be of clinical interest. Taking the most deviant groups for calculating sample size for different groups and assuming mean OS in these groups as mean $1=3.7 \mathrm{~mm}$, mean $2=3.5 \mathrm{~mm}$, taking $\mathrm{SD}=0.32, \alpha=0.05$, to achieve a power of $80 \%$, a sample size of 40 cases would be required in each group. Taking into account the possibility of a $25 \%$ dropout in the follow-up visits, we estimated the sample size to be 50 eyes in each group.

\section{Eligibility criteria}

Inclusion criteria were local residents with presence of senile cataract, age more than 45 years, pupil dilating more than $7 \mathrm{~mm}$ and eyes in which biometry, using the principle of partial coherence interferometry (IOLMaster ${ }^{\circledR}$; Carl Zeiss Meditec, Germany) was possible. Exclusion criteria included corneal scars, glaucoma, shallow anterior chamber (preoperative ACD) $<2.5 \mathrm{~mm}$ ), uveitis, very high myopia (axial lengths $>27 \mathrm{~mm}$ ), ${ }^{12}$ hypermetropes (axial length $<21 \mathrm{~mm}$ ), pseudoexfoliation, white mature cataracts, traumatic cataracts, visible zonulolysis, histories of previous intraocular surgeries, laser treatment, low signal-to-noise ratio on PCI scans, any posterior segment pathology, and patients with allergies to dilating drops. A single eye of each patient was recruited for the study.

\section{Surgical technique}

A single surgeon (ARV) performed all the surgeries, using topical anaesthesia after maximal dilatation of the pupil. A temporal clear corneal incision of 2.65 was made; the anterior chamber was reformed using the soft shell technique wherein a dispersive viscoelastic Viscoat $^{\mathbb{R}}$ (Alcon Laboratories, Fort Worth, TX, USA) was injected initially and the cohesive viscoelastic Provisc ${ }^{\circledR}$ (Alcon Laboratories) was injected beneath to push the Viscoat towards the endothelium. ${ }^{13}$ In all the cases, an initial small rhexis (smaller than the optic size of $6 \mathrm{~mm}$ ) was performed. Cortico cleaving hydrodissection ${ }^{14}$ preceded rotation of the nucleus. ${ }^{15}$ Emulsification was performed using the Infiniti ${ }^{\circledR}$ (Alcon Laboratories) and a standardized surgical technique within the confines of the small CCC. ${ }^{16-18}$ This was followed by bimanual irrigation and aspiration to ensure thorough and complete cortex removal. An AcrySof ${ }^{\mathbb{R}}$ SA60AT (Alcon Laboratories; $6 \mathrm{~mm}$ optic and $13 \mathrm{~mm}$ diameter) was implanted in the bag. IOL power was calculated preoperatively in all the patients using an IOLMaster ${ }^{\circledR}$.

At this stage (before viscoelastic removal), randomization was done on a computer-generated list. The eyes were randomly assigned to one of the three groups. Group I eyes had total cover of the anterior capsule on the IOL optic $\left(360^{\circ}\right)$. Group II eyes had partial cover of the anterior capsule on the IOL optic. Group III eyes had practically no cover of the anterior capsule on the IOL optic except at the optic-haptic junction. Eyes with $<1$ clock hours of cover were recruited in group III $\left(<330^{\circ}\right)$. The eyes on the list were randomly assigned any number from 1 to 150 . Corresponding to each number a single procedure was written (groups I, II, or III). Each patient was allocated a number sequentially. An operating room assistant, otherwise uninvolved in the study, informed the surgeon about the allocation of each eye to the particular group after the IOL implantation. For group I, if the anterior capsule cover was central, viscoelastic removal was performed immediately. For group II, enlargement of the rhexis was performed only partially. For group III, the anterior chamber was formed with viscoelastics to push the rim of the anterior capsule posteriorly. The rhexis was enlarged $360^{\circ}$ circumferentially using an iris spatula introduced through the side port that was placed immediately below the anterior capsule. ${ }^{19,20}$ The cystotome needle was introduced through the main incision and was placed on the iris spatula. A gentle touch and slight movement of the spatula toward the margin of the CCC created a break in continuity. After the needle and iris spatula were withdrawn, CCC forceps were used to grasp the tear and convert it into a flap, which was slowly manoeuvered around, enlarging the 
original opening. In the process, the flap was regrasped several times and care was taken to ensure that the edge of the rhexis was peripheral to the optic edge. ${ }^{21}$ In groups II and III, the total clock hours of the optic covered with anterior capsule was noted after centering the IOL in the capsular bag, intraoperatively. After the surgery, all the patients used topical steroids and antibiotics 4 times a day for 1 month, thereafter tapering the eye drops every 1 week. Tropicamide (1\%; Sunways India Pvt Ltd, Mumbai, India) eye drops were used at bedtime for 1 week.

\section{Patient examination}

The patients were examined on the first postoperative day, and thereafter at 1 month and 6 months for visual acuity and intraocular pressure measurements. Slit-lamp and fundus examinations were also carried out in these follow-up visits. At 6 months, the examiner who performed and analyzed the measurements was masked to the anterior capsule cover of the IOL optic.

Appropriate counselling about the side effects of Pilocarpine and Cyclopentolate eyedrops was done before instillation. Cyclopentolate 1\% (Pentolate; Deep Care Health Pvt Ltd, Dholka, India) was instilled twice 5 min apart. Cycloplegic ACD measurements were taken $30 \mathrm{~min}$ after application of the first drop. In a separate visit, 1 week later, pilocarpine nitrate $2 \%\left(\right.$ Carpinol $^{\circledR}$; Sunways India Pvt Ltd, Mumbai, India) was instilled twice $5 \mathrm{~min}$ apart. ACD was measured using the IOL Master $30 \mathrm{~min}$ after instillation of the first drop. ${ }^{8}$ An average of at least five ACD measurements with a difference of $<0.02 \mathrm{~mm}$ was considered for analysis. The OS was measured as a difference in ACD after instillation of Cyclopentolate 1\% and subsequent instillation of Pilocarpine $2 \%$ at two separate visits.

\section{Image analysis}

Standardized high-resolution digital retro-illumination photographs were shot using a Nikon D1H digital camera mounted on a Nikon Zoom photo-slit lamp flash pack through a fiber optic cable. ${ }^{22}$ The examiner grouped the images in one of the following groups: group I, group II, or group III. The digital images were transferred to the computer and stored in a tagged image file format (TIFF) for later evaluation. The TIFF images were converted into JPEG format in Adobe Photoshop version 7. The images in the JPEG format, were imported to the image analysis software, Softimage ${ }^{\mathrm{TM}}$ (Version 2.4, Soft Express

Solutions, Ahmedabad, India). The total optic edge and the CCC edge were outlined for all the images and stored in an Excel file. The total area of the IOL optic $\left(\mathrm{mm}^{2}\right)$ and the area of the optic within the CCC $\left(\mathrm{mm}^{2}\right)$, that is central to the rhexis margin were calculated. The percentage area of the rim of the anterior capsule covering the IOL optic was then calculated as follows:

- Percentage area of the optic central to the CCC $(\%)=$

$$
\frac{\text { Area of the CCC }\left(\mathrm{mm}^{2}\right) \times 100}{\text { Area of the IOL optic }\left(\mathrm{mm}^{2}\right)}
$$

- The percentage area of the rim of the anterior capsule covering the optic

(\% area of capsule cover) $(\%)$

$=100$ percentage area of the optic central to the $\mathrm{CCC}(\%)$

A higher percentage area of the capsule cover indicates a wide rim of CCC covering the IOL optic edge for $360^{\circ}$ or a wide rim of anterior capsule partially covering the IOL optic edge for $<360^{\circ}$ (Figures 1 and 2). A smaller

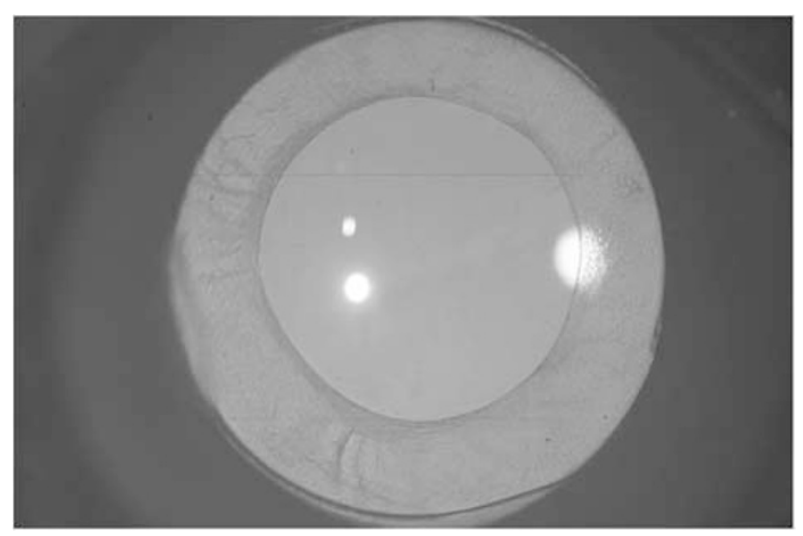

Figure 1 Representative photographs of an eye with maximum cover in group I (total cover).

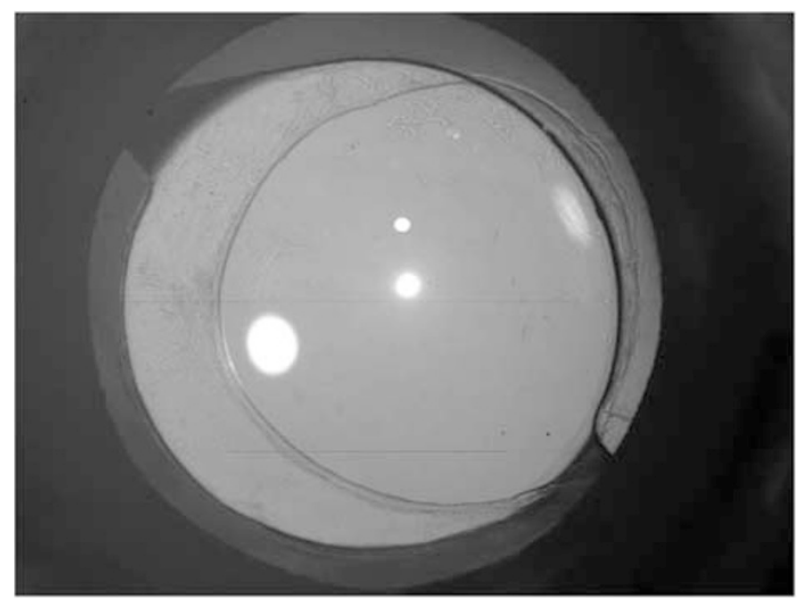

Figure 2 Representative photographs of an eye with maximum cover in group II (partial cover). 


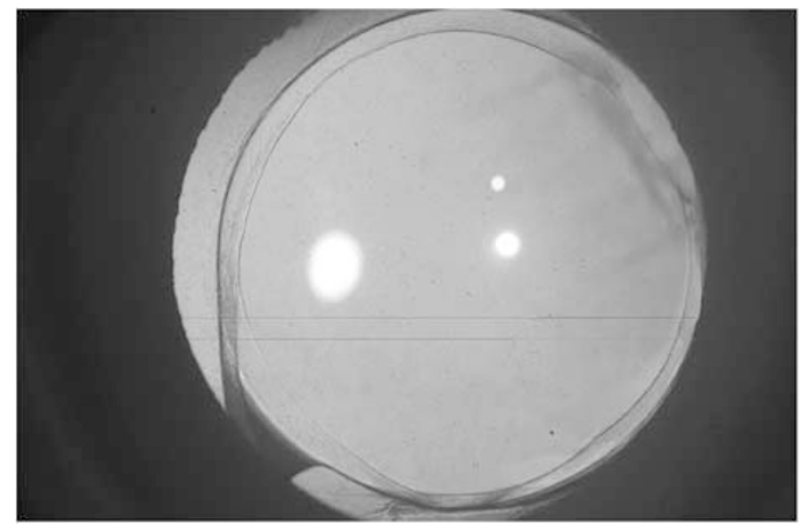

Figure 3 Representative photographs of an eye with least cover in group I (total cover).

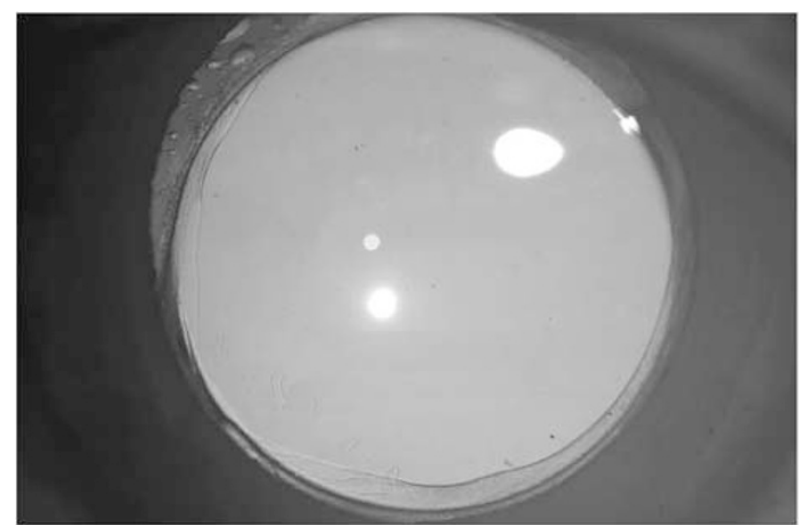

Figure 4 Representative photographs of an eye with least cover in group II (partial cover).

percentage area of the capsule cover indicates a thin rim of CCC covering the IOL optic edge for $360^{\circ}$ or a thin rim of anterior capsule partially covering the IOL optic edge for $<360^{\circ}$ only (Figures 3 and 4 ) or a wide rim for a few clock hours.

The main outcome measure was a change in the OS within and between groups.

\section{Statistical analysis}

Data from the evaluation forms were entered into a Microsoft Excel sheet. All further evaluation was carried out using standard software (Excel (Microsoft Office Excel) and SPSS (release 10.0 for windows, SPSS Inc.)). We hypothesized that the OS of the IOL was dependent on the percentage of the optic area covered by the anterior capsule. A $t$-test for equality of means was applied to the values of the optic shift, to find out the difference in the OS of the IOL in groups with some cover (groups I and II) $v s$ those with no cover (group III). In group III, the percentage area of the optic cover was observed to be constant (zero) as there was practically no cover. Therefore, we did not analyze the relationship between the capsule covering the optic and the OS in this group, as one was variable and the other constant.

The percentage area of the optic cover was divided into quartiles for better quantification of the change in the OS $(\mathrm{mm})$ as the measurements of the optic cover and OS were too minute to detect a sizeable change after arranging them in ascending order. Quartiles divide the observations into $25 \%$ equal classes. A correlation and regression test was applied to test the relationship between the OS and the percentage area of the optic cover. (The regression coefficient was also significant when raw observations of the percentage area of the optic cover were used in the analysis, instead of quartiles.) When the percentage area of the optic cover and OS where analyzed separately for total cover (group I) and partial cover (group II) using regression, the coefficients were significant in both the groups. However, the test of comparison of regression showed no significant difference between the coefficients of total cover in group I and partial cover in group II. So we merged the total cover (group I) and partial cover (group II) groups. The data of percentage area of the anterior capsule rim covering the optic (\% area of capsule cover) was arranged in ascending order for creating quartiles ( $25 \%$ classes) of capsule cover. A quartile is any of the three values which divide the sorted data set into four equal parts, so that each part represents one-fourth of the sample or population.

The quartile classes are as follows: upto $29.99 \%$ cover in the first quartile; $30-40 \%$ in the second quartile; $40.01-47 \%$ in the third quartile; $>47.01 \%$ in the fourth quartile. Linear regression analysis was applied to assess the impact of change in the quartile of area of the optic cover $(\%)$ on the OS $(\mathrm{mm})$.

\section{Results}

A total of 150 eyes were enrolled in this study. Table 1 shows the baseline characteristics of the eyes in all the three groups. On follow-up, 4/50 eyes in group I had partial cover and $2 / 50$ eyes in group II had no cover. Thus 46 eyes were enrolled in group I, 52 eyes in group II, and 52 eyes in group III after confirming the capsule cover. None of the eyes were excluded from the study due to unanticipated manipulation. Twenty-one patients did not attend the subsequent follow-ups after an initial observation and two did not give consent for Pilocarpine instillation after the first visit. Hence $8 / 46$ eyes in group I, 8/52 eyes in group II, and 7/52 eyes in group III were excluded from the study (the dropout rate was 13\%). In the final count there were 38 eyes in group I, 44 eyes in 
group II, and 45 eyes in group III (a total of 127 eyes) for data analysis.

Table 1 shows the demography and ocular parameters in all the groups. The mean follow-up was $59.1 \pm 1.4$, $60.9 \pm 1.9,58.2 \pm 2.1(P=0.934)$ months in each group. At 6 months, the mean OS $(\mathrm{mm}) \pm$ (range) in group I was $1.25 \pm 0.28$ (0.81-1.93); in group II was $1.20 \pm 0.24$ (0.70-1.55]; and in group III was $0.95 \pm 0.26(0.51-1.41)$ $(P=0.013)$, respectively. The percentage area of capsule cover $(\%) \pm$ (range) in group I was $47.35 \pm 10.48$ (25.53, 65.0); in group II was $33.83 \pm 10.11(19.72,56.30)$; and in group III was $0.16 \pm 0.13(0,1.2)(P=0.001)$, respectively. All the three groups differed significantly in the percentage area of optic cover (\%) and OS ( $\mathrm{mm})$. The $t$-test for equality of means was applied to the values of the OS to determine the difference in OS between some cover (groups I and II) vs no cover (group III). There was a significant difference between the groups $(P=0.004$, $(0.06,0.33))$. When groups I (total cover) vs II (partial cover) were compared, they differed significantly in terms of the percentage area of the optic cover $(P=0.001)$ but did not differ significantly in terms of the mean OS $(P=0.46)$ (Table 2$)$.

After taking both the groups together, the correlation coefficient between the anterior capsule cover and the OS was $0.37(P<0.05)$. The regression analysis given in

Table 1 Baseline characteristics of eyes in all the three groups

\begin{tabular}{|c|c|c|c|c|}
\hline & $\begin{array}{l}\text { Total cover (group I) } \\
\quad(\mathrm{n}=38 \text { eyes })\end{array}$ & $\begin{array}{l}\text { Partial cover (group II) } \\
\quad(\mathrm{n}=44 \text { eyes })\end{array}$ & $\begin{array}{l}\text { No cover (group III) } \\
(\mathrm{n}=45 \text { eyes })\end{array}$ & P-value \\
\hline \multicolumn{5}{|l|}{ Gender } \\
\hline Male & 20 & 30 & 29 & 0.15 \\
\hline Female & 18 & 14 & 16 & \\
\hline \multicolumn{5}{|l|}{ Age (years) } \\
\hline Mean \pm SD & $56.68 \pm 6.38$ & $57.09 \pm 7.34$ & $59.15 \pm 6.3$ & 0.21 \\
\hline Range & $25(4 \overline{4}-69)$ & $28(40-68)$ & $23(46-69)$ & \\
\hline \multicolumn{5}{|c|}{ Axial length (mm) } \\
\hline Mean \pm SD & $23.38 \pm 1.38$ & $23.70 \pm 1.08$ & $23.26 \pm 1.04$ & 0.19 \\
\hline Range & $5.32(21.02-26.34)$ & $4.36(21.48-25.84)$ & $3.97(21.4-25.37)$ & \\
\hline
\end{tabular}

Table 2 Summary of data

\begin{tabular}{|c|c|c|c|c|c|}
\hline Parameters & & $\begin{array}{l}\text { Total cover (group I) } \\
\quad(\mathrm{n}=38 \text { eyes })\end{array}$ & $\begin{array}{l}\text { Partial cover (group II) } \\
\quad(\mathrm{n}=44 \text { eyes })\end{array}$ & P-value & $\begin{array}{c}\text { Total cover }+ \text { partial } \\
\text { cover (combined) } \\
(n=82 \text { eyes })\end{array}$ \\
\hline \multirow{2}{*}{$\begin{array}{l}\text { Percentage area of } \\
\text { capsule cover }(\%)\end{array}$} & Mean \pm SD & $47.35 \pm 10.48$ & $33.83 \pm 10.11$ & \multirow[t]{2}{*}{$0.001^{*}$} & $40.10 \pm 12.26$ \\
\hline & $\begin{array}{l}\text { Range (minimum, } \\
\text { maximum) }\end{array}$ & $39.47(25.53,65.00)$ & $36.58(19.7256 .30)$ & & $45.28(19.7265 .00)$ \\
\hline Optic shift (mm) & $\begin{array}{l}\text { Mean } \pm \text { SD } \\
\text { Range (minimum, } \\
\text { maximum) }\end{array}$ & $\begin{array}{c}1.25 \pm 0.28 \\
1.12(0.811 .93)\end{array}$ & $\begin{array}{c}1.20 \pm 0.24 \\
0.85(0.671 .55)\end{array}$ & $0.46^{\dagger}$ & $\begin{array}{c}1.22 \pm 0.26 \\
1.23(0.671 .93)\end{array}$ \\
\hline
\end{tabular}

*The percentage area of the capsule cover in group I $v s$ group II is significant $P=0.001$ (unpaired $t$-test).

'The mean optic shift in group I vs group II is not significant. $P=0.46$ (unpaired $t$-test).

Table 3 Results of the regression in groups I and II combined (total cover and partial cover)

\begin{tabular}{llrrrr}
\hline & Model & Unstandardized coefficients & T & P-value \\
\cline { 3 - 4 } & & B & Std. error & \\
\hline Total on + part on Combined $(n=82$ eyes) $)$ & Constant & 0.72 & 0.117 & 6.156 & 0.000 \\
& Percentage area of capsule cover & 0.12 & 0.003 & 3.761 & 0.000
\end{tabular}

Adjusted $R^{2}=0.25$. 
Table 3 indicates that for the cover groups together (groups I and II combined) as we move from a lower quartile to an higher one of capsule cover; for each increment in quartile; the OS increases by $0.12 \mathrm{~mm}$ (Figures 5 and 6). Thus, the greater the optic area covered by the rim of anterior capsule the higher the optic shift. (The regression coefficient was also significant when observations of percentage area of optic cover were used in the analysis, instead of quartiles but the change was too small in numeric terms, hence quartiles were used).

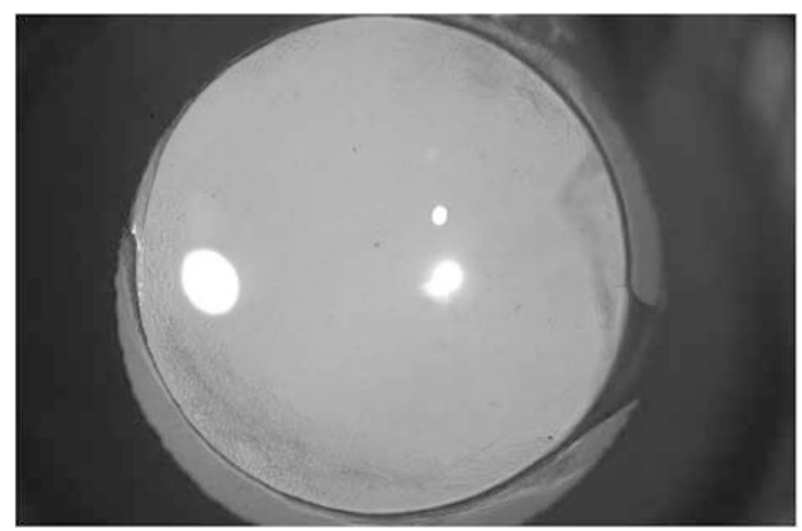

Figure 5 Representative photograph of an eye with practically no cover in group III (total off).

\section{Discussion}

This study measured the OS of a single piece monofocal IOL with varying relationships between the anterior capsule cover and the IOL optic. OS differed significantly between the cover groups (total on and partial on) vs the no cover group. OS did not differ significantly between the total and partial cover groups. Among the total and partial cover groups, the OS was proportional to the area of the anterior capsule cover on the optic and not on the clock hours covered.

OS has been observed following in-the-bag IOL implantation with different IOL types and designs with varying results. ${ }^{3,5,7,8,11,12,23,24}$ OS using pharmacological technique has been demonstrated to be $0.08 \pm 0.26 \mathrm{~mm}$ for polymethyl methacryclate (PMMA), ${ }^{5} 0.42 \pm 0.46 \mathrm{~mm}$ for hydrogel $\mathrm{IOL}^{5}$ and $0.28 \pm 0.38 \mathrm{~mm}$ for foldable silicone IOL. ${ }^{25}$ Moreover, Fukasaku and Marron ('Accommodation' video presented at the XVIth Congress of the European Society of Cataract \& Refractive Surgeons, Nice, France, September 1998), using ultrasound biomicroscopy, showed that the IOL moves anteriorly by a mean of $0.32 \mathrm{~mm}$ during near vision; whereas Lesiewska-Junk $\mathrm{H}$ and Kahuzny J showed a mean shift of $0.42 \mathrm{~mm}$ without any medication. ${ }^{7}$ However, these studies have not correlated the OS (axial IOL movement) with the anterior capsule

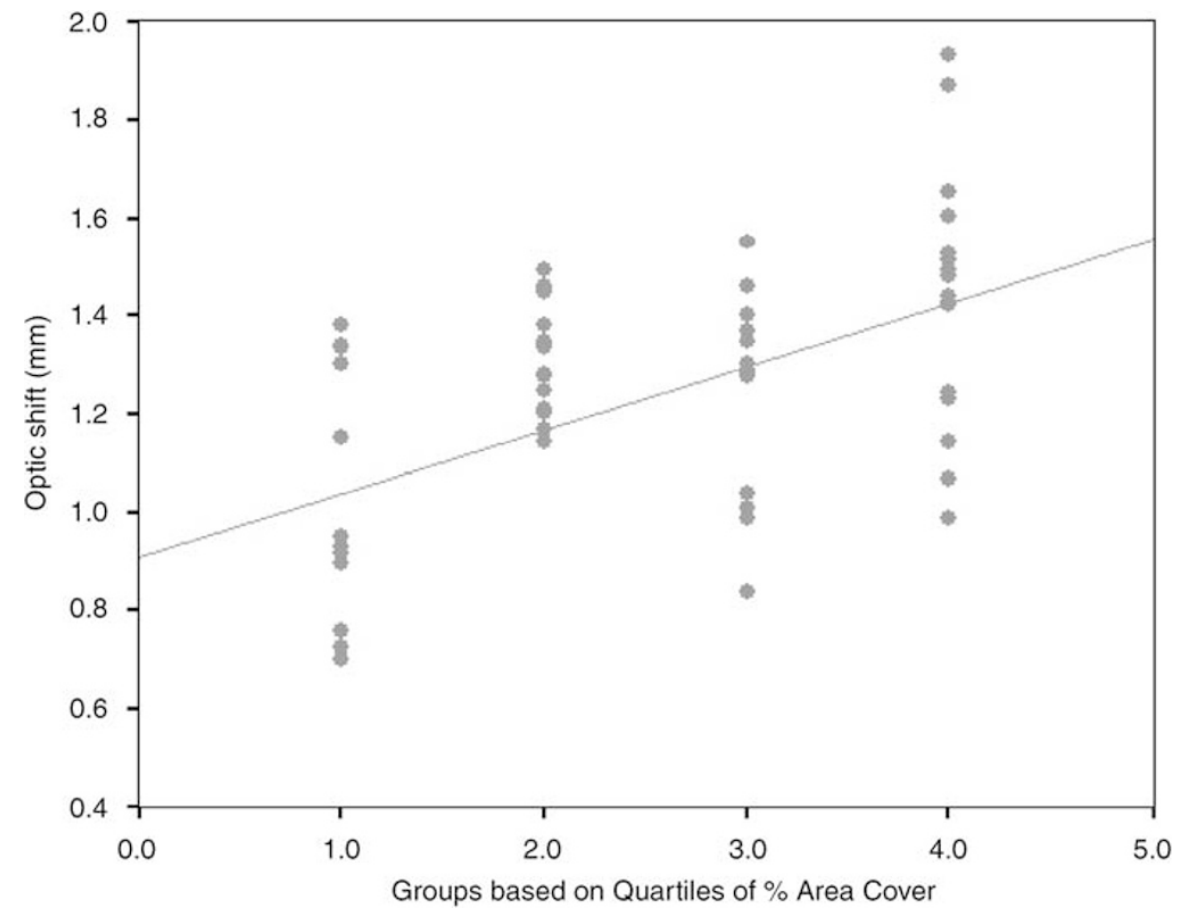

Figure 6 A scatter diagram of OS in each quartile in total cover and partial cover groups. The regression line indicates a proportionate average increase in shift by increase in quartile of optic area cover. 
cover. With the single piece AcrySof IOL, it has been reported that there is no significant OS compared to the three piece AcrySof design. ${ }^{3}$ This study evaluated OS in eyes with a CCC that completely covered the IOL optic. We designed this study to evaluate if any difference exists in the OS of the IOL, if the relationship of the CCC to the IOL optic is varied. The width of the anterior capsule rim covering the optic was also varied so that any overlap in the total cover and partial cover groups ranged from least cover to most cover (Figures 1-4).

In this study, we recruited only presbyopic patients as the accommodative forces in young pseudophakic eyes may be different. ${ }^{7}$ Eyes with axial length between 21 and $27 \mathrm{~mm}$ were recruited to rule out the influence of axial length on the IOL shift. ${ }^{12,26,27}$ The overall capsular bag size is higher in myopes; hence myopes will have a lower OS of the IOL as the accommodative forces of the ciliary muscles will be negated with a larger bag size. However, in hypermetropes, these forces would have a pronounced effect on the optic shift. Biometric calculations with an IOLMaster $^{\circledR}$ is not possible in eyes with dense opacities, such as brunescent and black cataracts, posterior capsular plaques, total white mature cataracts, and posterior polar cataracts. Hence, only those eyes in which biometry was possible using an IOLMaster ${ }^{\circledR}$ were recruited in the study.

The OS can be measured using objective methods such as anterior segment optical coherence tomography, ultrasound biomicroscopy, ${ }^{8}$ or Scheimpflug imaging system. ${ }^{28,29}$ We measured the OS by applying the pharmacological method in which we calculated the difference in the ACD..$^{3,10,11,24,30-35}$ Although this is an indirect method, it is well-accepted as it does not rely on patient compliance during the measurement procedure. ${ }^{3}$ Even though these pharmacological stimuli are nonphysiological, they are reported to be useful to find out the maximum potential of the optic shift. ${ }^{36}$ Lesiewska Junk $\mathrm{H}$ and Kaluzny J measured the IOL shift as a difference in ACD during fixation at $5 \mathrm{~m}$ and then at $40 \mathrm{~cm}^{7}$

ACD measurement with immersion A-Scan ultrasonography ${ }^{23,24,30,31}$ uses a contact method and accuracy depends on the experience of the examiner and compliance of the patient and results are difficult to interpret in pseudophakic eyes. ${ }^{37,38}$ The Zeiss AC master would have been a better alternative in pseudophakic eyes. ${ }^{39}$ as the IOL master uses partial coherence interferometry for measurement of axial length but slit-lamp photography for measurement of the ACD. We preferred to use the IOL Master as it allows non-contact biometry and therefore does not depend on the experience of the examiner and compliance of the patient. Although the results might differ owing to measuring principles inherent to the system, ACD was measured with an IOLMaster ${ }^{\circledR}$ in the present study as this is an established method. ${ }^{11,37,40-45}$ To avoid significant measurement differences related to imprecisions of the measurement method, we used the same method to measure the ACD in all the groups. We measured the OS at the end of 6 months as anterior capsule fibrosis causes a small backward shift of the IOLs and a slight enlargement in the CCC area with both multi-piece and single-piece IOL designs between 1 and 6 months. ${ }^{3}$ Moreover, because the single-piece IOL shifts minimally, spectacles can be prescribed sooner than for eyes implanted with multi-piece IOLs. ${ }^{3}$

The OS in the present study significantly differed between the cover groups (groups I and II combined) and the noncover group (group III). Contrary to our expectations, the OS also differed within the total cover group. Eyes with a thin rim of total cover demonstrated a lower OS compared to those with a larger rim of anterior capsule covering the IOL optic. This was also observed in eyes with partial cover. The average OS in this study is more than what has been observed in another study in which a drug-induced method and UBM (Ultrasonic Biomicroscope) were used for assessment, that is, $-0.111 \pm 0.125$ and $-0.047 \pm 0.139$, respectively. ${ }^{46}$ The reasons could be that the age group of patients included in that study population was between 40 and 83 years. Their range of follow-up of 3-31 months was also too large and the relation of the IOL to the anterior capsule has not been mentioned. ${ }^{46}$

Muftuoglu et $a l^{9}$ correlated the CCC diameter to the magnitude of the OS using a three-piece AcrySof IOL (MA30BM or MA60BM) and reported that it did not correlate. Although the CCC diameter was $5.16 \pm 0.26$, the relationship of the anterior capsule to the IOL edge has not been considered. Wirtitsch et $a l^{3}$ analyzed the stability of the three-piece AcrySof as compared to the single piece Acrysof IOL. They reported a minimal backward shift in the single-piece Acrysof IOL by $0.031 \mathrm{~mm}$ in eyes with a total cover using the PCI. This is lower than the results of this study.Their results show a large difference from our results probably because they have included both the SA30AL IOL (optic diameter $5.5 \mathrm{~mm}$ and overall diameter $12.5 \mathrm{~mm}$ ) and SA60AT IOL (optic diameter $6.0 \mathrm{~mm}$ and overall diameter $13.0 \mathrm{~mm}$ ) models and have not used any pharmacological agent while measuring ACD. ${ }^{3}$ Moreover, the aim of their study differed from ours.

The limitation of our study is that we have not quantified the size of the anterior CCC to the OS and have not correlated it with visual performance. Our study has shown that more the anterior capsule cover, the higher is the optic shift. However, it is also known that a smaller CCC (greater cover) can increase the risk of anterior capsule fibrosis, which can lead to phimosis of 
the CCC opening, ${ }^{4-51}$ and a larger CCC (small amount of cover) can increase the risk of IOL decentration and $\mathrm{PCO}^{52}$ This is of immense importance as the correlation of the size of CCC to the OS can be detrimental to the refractive status after multifocal IOL implantation.

Our study opens up avenues for further research to quantify the relationship between the exact size of the anterior CCC and OS correlating it with visual performance of monofocal IOLs of different materials and designs. Knowledge of the factors influencing the postoperative OS may allow for a better prediction of the final IOL position in patients before the lens is implanted and, therefore, could improve the overall surgical outcome. These outcomes could also help refine IOL designs for optimal, predictable performance in the capsular bag.

To summarize, this is a baseline study assessing the change in axial position of a single-piece monofocal Acrysof IOL (SA60AT) in varying relationships of anterior capsule overlap to the IOL optic edge. The results indicate that there is a correlation between the anterior capsule cover of the monofocal IOL optic and its optic shift. The more the anterior capsule cover on a single-piece AcrySof, the greater would be the axial movement of this IOL.

\section{References}

1 Langenbucher A, Seitz B, Huber S, Nguyen NX, Kuchle M. Theoretical \& measured pseudophakic accommodation after implantation of a new accommodative posterior chamber intraocular lens. Arch Ophthalmol 2003; 121: 1722-1727.

2 Langenbucher A, Huber S, Nguyen NX, Seitz B, GusekSchneider GC, Kuchle M. Measurement of accommodation after implantation of an accommodation posterior chamber intraocular lens. J Cataract Refract Surg 2003; 29: 677-685.

3 Wirtitsch MG, Findl O, Menapace R, Kriechbaum K, Koeppl $\mathrm{C}$, Buehl $\mathrm{W}$ et al. Effect of haptic design on change in axial lens position after cataract surgery. J Cataract Refract Surg 2004; 30: 45-51.

4 Koeppl C, Findl O, Menapace R, Kriechbaum K, Wirtitsch $\mathrm{M}$, Buehl W et al. Pilocarpine-induced shift of an accommodating intraocular lens: AT-45 Crystalens. J Cataract Refract Surg 2005; 31: 1290-1297.

5 Gonzalez F, Capeans C, Santos L, Suarez J, Cadarso L. Anteroposterior shift in rigid and soft implants supported by the intraocular capsular bag. Graefes Arch Exp Ophthalmol 1992; 230: 237-239.

6 Findl O, Drexler W, Menapace R, Bobr B, Bittermann S, Vass $\mathrm{C}$ et al. Accurate determination of effective lens position and lens-capsule distance with 4 intraocular lenses. J Cataract Refract Surg 1998; 24: 1094-1098.

7 Lesiewska-Junk H, Kahuzny J. Intraocular lens movement and accommodation in eyes of young patients. J Cataract Refract Surg 2000; 26: 562-565.
8 Findl O, Kiss B, Petternel V, Menapace R, Georgopoulos M, Rainer $\mathrm{G}$ et al. Intraocular lens movement caused by ciliary muscle contraction. J Cataract Refract Surg 2003; 29: 669-676.

9 Muftuoglu O, Hosal BM, Karel F, Zilelioglu G. Drug-induced intraocular lens movement and near visual acuity after AcrySof intraocular lens implantation. J Cataract Refract Surg 2005; 31: 1298-1305.

10 Vargas LG, Auffarth GU, Becker KA, Rabsilber TM, Holzer MP. Performance of the ICU accommodating intraocular lens in relation to capsulorhexis size. J Cataract Refract Surg 2005; 31: 363-368.

11 Cekic O, Batman C. The relationship between capsulorhexis size and anterior chamber depth relation. Ophthalmic Surg Lasers 1999; 30: 185-190.

12 Nawa Y, Ueda T, Nakatsuka M, Tsuji H, Marutani H, Hara Y et al. Accommodation obtained per $1.0 \mathrm{~mm}$ forward movement of a posterior chamber intraocular lens. J Cataract Refract Surg 2003; 29: 2069-2072.

13 Arshinoff SA. Dispersive-cohesive viscoelastic soft shell technique. J Cataract Refract Surg 1999; 25: 167-173.

14 Fine IH. Cortical cleaving hydrodissection. J Cataract Refract Surg. 2000; 26: 943-944.

15 Vasavada AR, Raj SM, Johar K, Nanavaty MA. Effect of hydrodissection alone and hydrodissection combined with rotation on lens epithelial cells: surgical approach for the prevention of posterior capsule opacification. J Cataract Refract Surg. 2006; 32: 145-150.

16 Vasavada AR, Singh R. Step-by-step, chop in situ and separation of very dense cataracts. J Cataract Refract Surg 1998; 24: 156-159.

17 Vasavada AR, Desai JP. Stop, chop, chop, and stuff. J Cataract Refract Surg 1996; 22: 526-529.

18 Vasavada AR, Raj S. Step-down technique. J Cataract Refract Surg 2003; 29: 1077-1079.

19 Vasavada AR, Desai J, Singh R. Enlarging the capsulorhexis. J Cataract Refract Surg 1997; 23: 329-331.

20 Vasavada AR, Shastri L. Initial and definitive capsulorhexes: an extended application. J Cataract Refract Surg 2000; 26: 634.

21 Vasavada AR, Raj SM. Anterior capsule relationship of the AcrySof intraocular lens optic and posterior capsule opacification: a prospective randomized clinical trial. Ophthalmology. 2004; 111: 886-894.

22 Pande MV, Ursell PG, Spalton DJ, Heath G, Kundaiker S. High-resolution digital imaging of the posterior lens capsule after cataract surgery. J Cataract Refract Surg 1997; 23: 1521-1527.

23 Ravalico G, Baccara F. Apparent accommodation in Pseudophakic eyes. Acta Ophthalmol (Copenh) 1990; 68: 604-606.

24 Nanavaty MA, Vasavada AR, Patel AS, Raj SM, Desai TH. Analysis of patients with good uncorrected distance and near vision after monofocal intraocular lens implantation. J Cataract Refract Surg 2006; 32: 1091-1097.

25 Legeais JM, Werner L, Werner L, Abenhaim A, Renard G. Pseudoaccommodation: BioConFold versus a foldable silicone intraocular lens. J Cataract Refract Surg 1999; 25: 262-267.

26 Holladay JT, Rubin ML. Avoiding refractive problems in cataract surgery. Surv Opthalmol 1988; 357-360.

27 Holladay JT. Standardizing constants for ultrasonic biometry, keratometry, and intraocular lens power calculations. J Cataract Refract Surg 1997; 23: 1356-1370.

28 Noda H, Nishida S, Ogino N, Ariki G, Tsunekawa M, Hayashi $\mathrm{H}$ et al. Objective evaluation of apparent 
accommodation of pseudophakic eyes. [Article in Japanese]. Nippon Ganka Gakkai Zasshi 1994; 98: 187-191.

29 Nakaizumi H, Sasaki K, Sakamoto Y. In vivo observation of axial movement of intraocular lenses through an anterior eye segment analysis system. Ophthalmic Res 1992; 24(Suppl 1): 21-25.

30 Hardman Lea SJ, Rubinstein MP, Snead MP, Haworth SM. Pseudophakic accommodation? A study of stability of capsular bag supported, one piece, rigid tripod, or soft flexible implants. Br J Ophthalmol 1990; 74: 22-25.

31 Nakazawa M, Ohtsuki K. Apparent accommodation in pseudophakic eyes after implantation of posterior chamber intraocular lenses. Am J Ophthalmol 1983; 96: 435-438.

32 Huber C. Myopic astigmatism as a substitute for accommodation in pseudophakia. Dev Ophthalmol 1981; 5: $17-26$.

33 Kuchle M, Nguyen NX, Langenbucher A, Gusek-Schneider GC, Seitz B, Hanna KD. Implantation of a new accommodative posterior chamber intraocular lens. J Refract Surg 2002; 18: 208-216.

34 Auffarth GU, Tetz MR, Biazid Y, Volker HE. Measuring anterior chamber depth with Orbscan Topography System. J Cataract Refract Surg 1997; 23: 1351-1353.

35 Fukuyama M, Oshika T, Amano S, Yoshitomi F. Relationship between apparent accommodation and corneal multifocality in pseudophakic eyes. Ophthalmology 1999; 106: 1178-1181.

36 Kriechbaum K, Findl O, Koeppl C, Menapace R, Drexler W. Stimulus-driven versus pilocarpine-induced biometric changes in pseudophakic eyes. Ophthalmology 2005; 112: 453-459.

37 Vetrugno M, Cardascia N, Cardia L. Anterior chamber depth measured by two methods in myopic and hyperopic phakic IOL implant. Br J Ophthalmol 2000; 84: 1113-1116.

38 Naeser K, Naeser A, Boberg-Ans J, Bargum R. Axial length following implantation of posterior chamber lenses. J cataract Refract Surg 1989; 15: 673-675.

39 Kriechbaum K, Findl O, Kiss B, Sacu S, Petternel V, Drexler W. Comparison of anterior chamber depth measurement methods in phakic and pseudophakic eyes. J Cataract Refract Surg 2003; 29: 89-94.

40 Koeppl C, Findl O, Kriechbaum K, Sacu S, Drexler W. Change in IOL position and capsular bag size with an angulated intraocular lens early after cataract surgery. J Cataract Refract Surg 2005; 31: 348-353.

41 Kriechbaum K, Findl O, Preussner PR, Koppl C, Wahl J, Drexler W. Determining postoperative anterior chamber depth. J Cataract Refract Surg. 200; 29: 2122-2126.

42 Findl O, Drexler W, Menapace R, Hitzenberger CK, Fercher AF. High precision biometry of pseudophakic eyes using partial coherence interferometry. J Cataract Refract Surg 1998; 24: 1087-1093.

43 Findl O, Drexler W, Menapace R, Heinzl H, Hitzenberger $\mathrm{CK}$, Fercher AF. Improved prediction of intraocular lens power using partial coherence interferometry. J Cataract Refract Surg 2001; 27: 861-867.

44 Findl O, Drexler W, Menapace R, Bobr B, Bittermann S, Vass $\mathrm{C}$ et al. Accurate determination of effective lens position and lens-capsule distance with 4 intraocular lenses. J Cataract Refract Surg 1998; 24: 1094-1098.

45 Drexler W, Baumgartner A, Findl O, Hitzenberger CK, Sattmann H, Fercher AF. Submicrometer precision biometry of the anterior segment of the human eye. Invest Ophthalmol Vis Sci 1997; 38: 1304-1313.

46 Urbak SF. Ultrasound biomicroscopy III. Accuracy and agreement of measurements. Acta Ophthalmol Scand 1999; 77: 293-297.

47 Davidson JA. Capsule contraction syndrome. J Cataract Refract Surg 1993; 19: 582-589.

48 Ursell PG, Spalton DJ, Pande MV. Anterior capsule stability in eyes with intraocular lenses made of poly-(methyl methacrylate), silicone, and AcrySof. J Cataract Refract Surg 1997; 23: 1532-1538.

49 Young DA, Orlin SE. Capsulorhexis contraction in phacoemulsification surgery. Ophthalmic Surg 1994; 25: 477-478.

50 Hansen SO, Crandall AS, Olson RJ. Progressive constriction of the anterior capsular opening following intact capsulorhexis. J Cataract Refract Surg 1993; 19: 77-82.

51 Spang KM, Rohrbach JM, Weidle EG. Complete occlusion of the anterior capsular opening after intact capsulorhexis: clinicopathologic correlation. Am J Ophthalmol 1999; 127: 343-345.

52 Schmidbauer JM, Vargas LG, Apple DJ, Escobar-Gomez M, Izak A, Arthur SN et al. Evaluation of neodymiumyttriumaluminum-garnet capsulotomies in eyes implanted with AcrySof intraocular lenses. Ophthalmology 2002; 109: 1421-1426. 